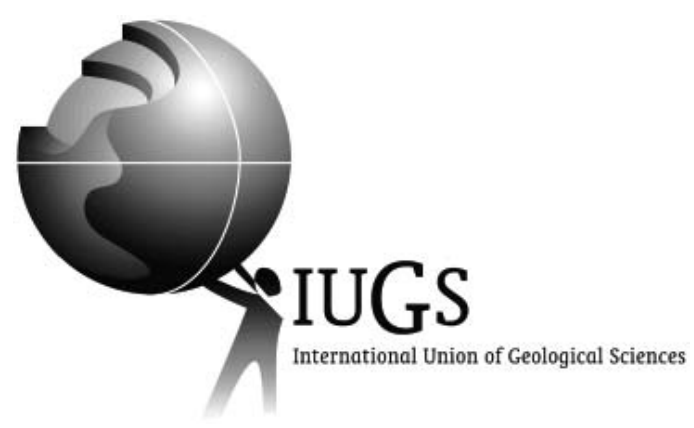

\section{From the Chair}

IUGS has a new logo. After forty years of service the Executive Committee considered it appropriate to exchange our traditional hammer-pierced globe for a model basically expressing our care for and balanced use of the Earth. The prominent exposure of the hammer in the logo was more and more questioned both inside and outside the geoscience community. Through its logo, the Union's image became more often associated with exploiting the Planet rather than promoting sustainable use of its natural resources.

That image, however, was incorrect. Particularly over the past decade the Union paid much attention to the use of earth materials in relation to the environment and to man's interaction with the Earth's processes in relation to risk for society. In 1990 the IUGS Commission on Geological Sciences for Environmental Planning was created and started its campaigns on these issues. That Commission published and distributed thousands of its brochure 'Planning and managing the human Environment, the essential role of the Geosciences' in four languages. From this Commission new initiatives emerged, such as the highly successful Geo-Indicators and Medical Geology Initiatives, the International Working Group on Urban Geology and Working Group on Land use and sustainable development. Furthermore, the IUGS Working Group on Fossil Fuels contributed much to a more effective and sustainable use of hydrocarbons, particularly in developing countries. More recently, the former Deposit Modelling Programme, a joint venture with UNESCO, was redesigned into a Mineral Resources Sustainability Program. In other Joint Programmes, such as IGCP and GARS, and in other IUGS Commissions, modifications along the same lines took place.

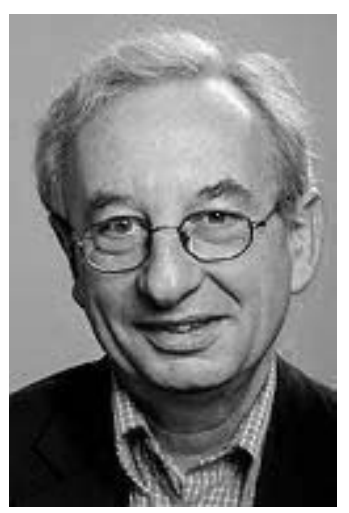

As the Union developed a more society-oriented image and fuelled by the recommendations of the Strategic Planning Committee in 2000, the new Executive Committee worked on materializing this trend more clearly in its exposure. The development of a new logo was a logic step in that direction. Shortly before last year's Executive Committee meeting in Lower Hutt, a logo-competition was announced for members of the IUGS family. Among the over one hundred submitted proposals the Executive Committee selected six most preferred. These were successively discussed, compared and commented upon by three external professional designers. The winning logo, designed by Han Bruinenberg of the Geological Survey of the Netherlands, simultaneously expresses the wise use and care of the Earth by the Geoscience community.

With this new logo the Executive Committee hopes to contribute to a better exposure of the work by the Union and to an improved performance of the geosciences in the service of society.

Eduardo F. J. de Mulder

President, International Union of Geological Sciences 